\title{
ANALISA KOMPARASI PRODUKTIVITAS KERJA ANTARA PEMBATIK HARIAN DAN PEMBATIK LEPAS ( STUDI KASUS DI KAMPOENG BATIK LAWEYAN SURAKARTA)
}

\author{
Rahma Khairun Nisa, Siti Maryam, Ida Aryati DPW \\ Fakultas Ekonomi, Universitas Islam Batik Surakarta \\ Email: rahmakhairunnisa47@gmail.com
}

\begin{abstract}
Abstrak : The objective to be achieved through this research is to find out the differences in productivity of daily batik workers and loose batik workers. In addition, it is also to find out whether there are differences in work motivation, work experience between daily batik and loose batik in Kampoeng Batik Laweyan Surakarta. The method used is a comparative descriptive method. The population in this study amounted to 665 batik and the sample used amounted to 100 people, where the sampling technique uses purposive sampling and convenience sampling techniques. The data used are secondary data and primary data with data collection techniques of observation, questionnaires, interviews. documentation and study of literature. Data analysis techniques in this study used the Independent T-test. Based on the results of research and discussion shows there are significant differences in work productivity between daily batik and loose batik, there are differences in work motivation and work experience of daily batik and loose batik.
\end{abstract}

Keywords: Work Productivity, Work Motivation and Work Experience

\section{PENDAHULUAN}

Transformasi batik yang lebih fashionable membuat permintaan pasar terhadap batik meningkat apalagi sejak dibukanya perdagangan bebas maka semakin banyak pilihan akan barang-barang kebutuhan pakaian batik, dengan banyaknya persaingan ini menjadi kekuatan pedagang dan pengusaha batik untuk meningktakan produksi batik (Erma \& Zulfikar, 2015). Meningkatnya sektor industri batik itu tidak terlepas oleh kegiatan UMKM di kawasan kampung batik dalam memproduksi kain batik yaang dihasilkan. Permintaan pasar yang meningkat juga tidak terlepas dari pekerja di industri itu salah satunya pembatik untuk mencapai produktivitas yang dihasilkan harus memiliki pekerja yang terampil dan berpengalaman. Produktivitas merupakan perbandingan antara hasil yang dicapai dengan peran serta tenaga kerja persatuan waktu. Peran serta disini adalah penggunaan sumber daya yang efisien dan efektif (Nahdiyyah dkk, 2018). Untuk meningkatkan produktivitas kerja pekerja industi batik diperlukan sumber daya manusia yang berketrampilan tinggi, berpengetahuan dan berpengalaman.

Motivasi menunjukan kondisi yang dapat menggerakan pekerja untuk melaksanakan pekerjaanya. Motivasi kerja sangat memengaruhi semangat kerja yang dimiliki oleh pekerja yang berpotensi untuk mencapai hasil yang optimal, sehingga dipeukan adanya pendorong agar pekeja mau mengarahkseluruh potensinya, motivasi memang bukan faktor satu-satunya dalam 
menggerakan karyawan agar selalu semangat dalam bekerja (Rahmawati dkk, 2016). Penelitian Laminia \& Muniroh (2018) menyatakan hubungan antara motivasi kerja dengan produktivtas kerja dimana sebagian responden memiliki motivasi kerja sangat baik dan dapat memenuhi target produksi.

Kesiapan kerja dipengaruhi oleh faktor yang bersal dari dalam meliputi kematangan fisik, kreativitas, minat bakat, kemandirian pengeusaan kerja dan motivasi. Adapun faktor eksternal berasal dari luar meliputi peran masyarakat, keluarga, sarana dan prasarana, informasi dan pengalaman kerja. Pengalaman adalah sumber pengetahuan dan pengalaman di peroleh karena adanya interaksi anatara individu dengan lingkungannya (Vitrianingsih \& Khadijah, 2017). Hasi penelitian Rismayadi (2015) menunjukkan bahwa antara tingkat pendidikan, usia kerja, motivasi dan pengalaman kerja memiliki pengaruh yang signifikan terhadap produktivitas kerja karyawan.

\section{LANDASAN TEORI}

\section{A. Produktivitas kerja}

Sedarmayanti (2011:57) menyatakan bahwa produktivitas adalah bagaimana menghasilkan atau meningkatkan hasil barang dan jasa setinggi mungkin dengan memanfaatkan sumber daya manusia secara efisien. Oleh karena itu produktivitas sering diartikan sebagai rasio antara keluaran dan masukan dalam satuan tertentu.

Produktivitas kerja merupakan suatu hal yang penting bagi suatu organisasi baik itu yang bergerak di bidang jasa maupun produksi barang. Konsep dasar dari produktivitas kerja terdiri dari daya guna (efesiensi) dan hasil guna (efektivtas). Menurut Umar (2010:99) bahwa produktivitas adalah sikap mental yang selalu berpandangan bahwa mutu kehidupan hari ini harus lebih baik dari hari kemarin dan esok hari harus lebih baik dari hari ini

\section{B. Motivasi kerja}

Menurut (Sutrisno, 2016) mengemukakan bahwa "Motivasi adalah suatu faktor yang mendorong seseorang untuk melakukan suatu aktifitas tertentu". Kemudian menurut (Mangkunegara, 2015) "Motivasi adalah kondisi yang menggerakan pegawai agar mampu mencapai tujuan dari motifnya."

Dalam buku manajemen sumber daya manusia dijelaskan bahwa "Motivasi" adalah kondisi mental yang mendorong dilakukannya suatu tindakan dan memberikan kekuatan yang mengarah kepada pencapaian kebutuhan, memberi kepuasan ataupun mengurangi ketidak sinambungan" (Martoyo, $2000: 165)$.

\section{Produktivitas kerja}

Menurut Siagian (2007:52), pengalaman kerja mengacu pada berapa lama seseorang bekerja, berapa banyak jenis pekerjaan atau jabatan yang pernah dilakukannya, dan berapa periode masa kerjanya pada masing-masing pekerjaan atau jabatan tersebut. Winardi mendefinisikan senioritas adalah masa kerja seorang pekerja bilamana diterapkan pada hubungan kerja maka senioritas adalah masa kerja seorang pekerja pada perusahaan tertentu (Winardi: 2009).

\section{Kerangka pemikiran}

Untuk memperjelas arah dan penentuan langkah-langkah penelitian serta pengelolaan data yang diperoleh dari penelitian ini dirumuskan dalam kerangka pemikiran. Dalam penulisan 
penelitian ini menitik beratkan pada analisis komparasi produktivitas kerja antara pekerja harian dan pekerja lepas para pembatik (studi kasus di kampoeng batik laweyan) Adapun kerangka pemikiran dalam penelitian ini adalah sebagai berikut:

\begin{tabular}{|c|c|}
\hline $\begin{array}{c}\text { Produktivitas } \\
\text { kerja } \\
\text { Pembatik } \\
\text { harian } \\
\end{array}$ & $\begin{array}{c}\text { Produktivitas } \\
\text { kerja } \\
\text { Pembatik harian }\end{array}$ \\
\hline $\begin{array}{c}\text { Motivasi kerja } \\
\text { Pengalaman } \\
\text { kerja }\end{array}$ & $\begin{array}{l}\text { Motivasi kerja } \\
\text { Pengalaman } \\
\text { kerja }\end{array}$ \\
\hline
\end{tabular}

\section{METODE PENELITIAN}

Penelitian ini merupakan penelitian ini yaitu metode deskriptif dan komparatif. Metode deskriptif adalah metode penelitian yang digunakan untuk mengetahui suatu keadaan tertentu, dimana hasilnya dijelaskan dalam bentuk laporan penelitian sedangkan metode komparatif adalah metode penelitian yang digunakan untuk membandingkan dua kelompok yang berbeda. Obyek penelitian ini adalah para pembatik yang ada di Kampoeng Batik Laweyan Surakarta. Populasi dalam penelitian berjumlah 665 orang. Sample yang diambil dalam penelitian ini adalah sebanyak 100 orang diambil dari 15\% dari populasi. Purposive sampling adalah teknik pengambilan sampel dengan kriteria tertentu yang sudah ditetapkan oleh peneliti dan Convinience Sampling adalah teknik pengambilan sampel dengan dasar kemudahan untuk mendapatkan sampel (Muhamad, 2009:175). Independent sample $t$ test merupakan alat analisis yang digunakan untuk membandingkan (membedakan) dua kelompok yang tidak memiliki hubungan. Penelitian ini menggunakan uji Independent sample t test untuk mencari perbedaan produktivitas kerja antara pembatik harian dan pembatik lepas.

\section{HASIL DAN ANALISIS DATA}

\section{A. Hasil uji homogenitas}

\begin{tabular}{lll}
\multicolumn{3}{l}{ Tabel 1 Hasil Uji Levene Test (Homogenitas Varians) } \\
\hline Variabel & Signifikansi & Ket \\
\hline Produktivitas Kerja & 0,487 & Homogen \\
Motivasi Kerja & 0,832 & Homogen \\
Pengalaman Kerja & 0,620 & Homogen \\
\hline
\end{tabular}

Sumber: Data primer yang diolah, 2020

Berdasarkan tabel 1 Menunjukkan bahwa seluruh variabel penelitian memiliki distribusi sampel yang berasal dari dua kelompok dengan populasi yang homogen ( $p$-value>0,05). 


\section{B. Hasil uji indepedent T-test}

1) Produktivitas kerja

\begin{tabular}{|c|c|c|c|c|}
\hline variabel & t hitung & $\mathrm{t}$ tabel & $\begin{array}{l}\text { Sig } \\
\text { (2- tailed) }\end{array}$ & Ket \\
\hline $\begin{array}{l}\text { Produktivitas } \\
\text { Kerja }\end{array}$ & 2.131 & 1.661 & 0,036 & Ho ditolak \\
\hline
\end{tabular}

Berdasarkan tabel 2 diatas dapat dilihat bahwa hasil dari pengujian tersebut didapat t hitung sebesar 2.131 nilai ini lebih kecil dari t tabel 1.661 signifikan pada 5\% (sig 2 tailed $0,036>0,05)$ maka Ho ditolak yang artinya terdapat perbedaan produktivitas kerja antara pembatik harian dan pembatik lepas.

\section{2) Motivasi kerja}

Tabel 3 Hasil uji independent $t$-test variabel Motivasi Kerja

\begin{tabular}{lcccc}
\hline variabel & t hitung & t tabel & $\begin{array}{c}\text { Sig } \\
(2-\text { tailed })\end{array}$ & Ket \\
\hline $\begin{array}{l}\text { Motivasi } \\
\text { Kerja }\end{array}$ & 3.104 & 1.661 & 0,002 & Ho ditolak \\
\hline
\end{tabular}

Sumber : Data primer yang diolah, 2020

Berdasarkan tabel 3 diatas dapat dilihat bahwa hasil dari pengujian tersebut didapat $\mathrm{t}$ hitung sebesar 3.104 nilai ini lebih besar dari t tabel 1.661 signifikan pada 5\% atau (sig 2 - tailed $0,002<0,05)$ maka Ho ditolak yang artinya terdapat perbedaan motivasi kerja antara pembatik harian dan pembatik lepas.

\section{3) Pengalaman kerja}

Tabel 4 Hasil uji independent t-test variabel Pengalaman Kerja

\begin{tabular}{|c|c|c|c|c|}
\hline variabel & t hitung & $\mathrm{t}$ tabel & $\begin{array}{l}\text { Sig } \\
\text { (2- tailed) }\end{array}$ & Ket \\
\hline Pengalaman Kerja & 2.209 & 1.661 & 0,030 & Ho ditolak \\
\hline
\end{tabular}

Berdasarkan tabel 4 diatas dapat dilihat bahwa hasil dari pengujian tersebut didapat t hitung sebesar 2,209 nilai ini lebih besar dari t tabel 1.661 signifikan pada 5\% (sig 2 - tailed 0,030 $<0,05)$ maka Ho ditolak yang artimya terdapat perbedaan pengalaman kerja antara pembatik harian dan pembatik lepas

\section{KESIMPULAN}

Berdasarkan hasil analisis dan pembahasan diatas mengenai perbedaan produktivitas kerja, motivasi kerja dan penagalaman kerja antara pembatik harian dan pembatik lepas di Kampoeng Batik Laweyan Surakarta, maka penulis dapat menarik kesimpulan sebagai berikut : 
1) Terdapat perbedaan yang signifikan variabel produktivitas kerja antara pembatik harian dan pembatik lepas di Kampoeng Batik Laweyan Surakarta. Hal ini menunjukkan hipotesis pertama yang menyatakan "Terdapat perbedaan produktivitas kerja antara pembatik harian dan pembatik lepas di Kampoeng Batik Laweyan " terbukti.

2) Terdapat perbedaan yang signifikan variabel motivasi kerja antara pembatik harian dan pembatik lepas di Kampoeng Batik Laweyan Surakarta. Hal ini menunjukkan hipotesis kedua yang menyatakan "Terdapat perbedaan motivasi kerja antara pembatik harian dan pembatik lepas di Kampoeng Batik Laweyan" terbukti.

3) Terdapat perbedaan yang signifikan variabel penagalaman kerja antara pembatik harian dan pembatik lepas di Kampoeng Batik Laweyan Surakarta. Hal ini menunjukkan hipotesis ketiga yang menyatakan "Terdapat perbedaan penagalaman kerja antara pembatik harian dan pembatik lepas di Kampoeng Batik Laweyan" juga terbukti.

\section{SARAN}

Saran yang dapat diberikan penulis sehubungan dengan hasil penelitian ini sebagai berikut :

1) Diharapkan produsen batik yang ada di Kampoeng Batik Laweyan Surakarta lebih memperhatikan lagi para buruh harian dan buruh lepas yang bekerja untuk meningkatkan kualitas produksi.

2) Diharapkan pengusaha Kampoeng Batik Laweyan Surakarta menciptakan suasana kerja yang mampu merangsang produktivitas kerja para pembatik. Hal tersebut dapat dilakukan dengan cara memperhatikan faktor- faktor yang mempengaruhi produktivitas kerja dan menanamkan rasa saling memiliki perusahaan, sehingga akan timbul rasa untuk ikut serta memelihara dan mempertahankan perusahaan.

3) Untuk para pembatik yang memiliki penagalaman cukup harus memberikan bimbingan dan masukan kepada pembatik pemula yang belum berpengalaman sehinagga mempermudah pembatik tersebut dalam bekerja.

4) Hasil penelitian ini juga bisa dijadikan bahan rujukan dalam hal pengembangan ke arah yang lebih positif bagi perusahaan dan lebih menekankan pada pengalaman kerja dan produktiavitas kerja.

\section{DAFTAR PUSTAKA}

Ahmad, D. (2007). Peningkatan Mutu Pendidikan Sebagai Sarana Pembangunan Bangsa. Jakarta: Balai Pustaka.

Anggriani, I., \& Saputra, A. R. (2019). Analisa Perbedaan Produktivitas Kerja Karyawan Tetap, Kontrak dan Pekerja Harian Lepas . Jurnal Illmiah Ekonomi dan Bisnis, 70-79.

Arikunto, S. (2012). Prosedur Penelitian Suatu Pendekatan Praktis Edisi Revisi Vi. Jakarta: PT Rineka Cipta.

Budiono, A. R. (1995). Hukum Perburuhan Di Indonesia. Jakarta: Rajawali Graindo Persada.

Dhanendra, D. G., \& Indrawati, K. R. (2018). Perbedaan Motivasi Kerja Dan Etos Kerja Antara Karyawan Pendatang Dengan Karyawan Non Pendatang Yang Bekerja Pada Hotel Bintangnahdiyyah Lima Di Bali. Jurnal Psikologi Udayana, 207-217. 
Erma, S., \& Zulfikar, N. d. (2015). Pengembangan Komoditas Batik : Determinasi Budaya Ekonomi Dan Perubahan Struktur Kebijakan Terhadap Perkembangan Usaha Ekonomi Lokal ( Studi Tentang Pengusaha Batik Laweyan). Jurnal Ekonomi dan Bisnis, 119-134.

Foster, B. (2001). Pembinaan Untuk Peningkatan Kinerja Karyawan . Jakarta: PPM.

Gunardi, Djoko Suseno, Y., \& Ernawati. (2016). Analisis Perbedaan Motivasi Keja, Loyalitas Kerja dan Kinerja Guru Yang Bersertifikasi Dengan Yang Belum Bersertfiakasi Kecamatan Kedawung Sragen. Jurnal Manajemen Sumber Daya Manusia, 57-66.

Gyeltshen, C., \& Beri, D. N. (2019). Comaparison On The Levels Of Work Place Happines ,Job Satisfication, Organizational Commitment And Work Motivatiion With Respect To Gender. International Journal Of Education, 15-32.

Hasibuan, M. (2003). Organisasi dan Motivasi Dasar Peningkatan Produktivitas. Jakarta: PT Bumi Aksara.

Hasibuan, M. S. (2005). Manajemen Sumber Daya Manusia. Edisi Revisi. Jakarta : PT Bumi Aksara.

Hasibuan, M. S. (2007). Manajemen Sumber Daya Manusia Perusahaan. Jakarta: PT Bumi Aksara.

Hasibuan, M. S. (2010). Manajemen Sumber Daya Manusia. Jakarta: PT Bumi Aksara.

Hasibuan, M. S. (2016). Manajemen Sumber Daya Manusia. Edisi Revisi. Jakarta: PT Bumi AKsara.

Idrus, M. (2009). Metode Penelitian Ilmu Sosial: Pendekata Kualitatif Dan Kuantiatif. Edisi Dua,. Jakarta: Erlangga.

laminia, D., \& Muniroh, L. (2018). Hubungan Motivasi Dan Masa Kerja Dengan Produktivitas Pekerja Di Home Industry. The Indonesian Journal Of Occupational Safety And Health, 241-248.

Lasut, E. E., Lengkong, V. P., \& Ogi, I. W. (2017). Analisis Perbedaan Kinerja Pegawai Berdasarkan Gender, Usia Dan Masa Kerja (Studi Pada Dinas Pendidikan Sitaro. Jurnal EMBA, 2771-2780.

Mandala, A., \& Raharja, E. (2012). Peran Pendidikan , Pengalaman dan Inovasi Terhadap Produktivitas Usaha Kecil Mengah. Diponegoro Journal of Management, 1-11.

Mangkunegara, A. (2015). Manajemen Sumber Daya Manusia Perusahaan. Bandung: Remaja Rosdakarya.

Manullang. (2008). Dasar-dasar Manajemen. Yogyakarta: Ghalia Indonesia.

Martoyo, S. (2000). Manajemen Sumber Daya Manusia. Yogyakarta: Bofe.

Maryam, S. (2015). Statistik Induktif. Surakarta: UNIBA Press.

Morais, O. F., Prastiwi, S., \& Sulasmini. (2019). Perbedaan Motivasi Kerja dan Tingkat Kedisiplinan Perawat PNS di Puskesmas Dinoyo dan Puskesmas Batu. Nursering News Jurnal Keperawatan, 67-78.

Nahdiyyah, I. R., Hidayat, M. T., \& Nursahidin. (2018). Perbandingan Produktivitas Kerja Pegawai Negeri Sipil Dengan Pegawai Badan Usaha Milik Negara (Studi Komparasi Di Sekretariat Daerah Kota Cirebon Dengan Pt. Kereta Api Indonesia (Persero) Daerah Operasi Iii Cirebon. Jurnal Publika, 30-55.

Pakpahan, M., \& Pakpahan, R. D. (2010). Konflik kepentingan outsourcing dan kontrak dalam UU No. 13 Tahun 2003 Edisi Dua. Jakarta: Erlangga. 
Purnama, F. A. (2012). Perbedaan Motivasi Kerja Antara Karyawan Kontrak Dan Karyawan Tetap Pada Pt. Bank Rakyat Indonesia Cabang Cimahi. Jurnal Ilmiah Psikologi, 566-581.

Rahmawati, P., Prihatini, D., \& Krishnabudi, N. (2016). Analisis Gender pada Motivasi Kerja, Stres Kerja, dan Disiplin Kerja Antara Tenaga Kependidikan Pria dan Wanita di Universitas Jember. Artikel Ilmiah Mahasiswa, 1-6.

Rismayadi, B. (2015). Faktor- faktor Yang Mempengaruhi Produktivitas karyawan ( Studi Kasus Pada CV Mitra Bersama Lestari Tahun 2014. Jurnal Manajemen Dan Bisnis, 1-16.

Rival, V. (2011). Manajemen Sumber Daya Manusia Untuk Perusahaan: Dari Teori Ke Praktik. Jakarta: PT Raja Grafindo.

Rondonuwu, L., Kawatu, P. A., \& Malonda, N. S. (2016). Hubungan Antara Motivasi Kerja Dengan Produktivitas Kerja Pada Tenaga Harian Lepas Di Badan Pengelolaan Lingkungan Hidup. Jurnal Ilmiah Farmasi, 304-312.

Sedarmayanti. (2011). Manajemen Sumber Daya Manusia, Reformasi Birokrasi Dan Manajemen Pegawai Negeri Sipil (Cetakan Lima). Bandung: PT. Refika Aditama.

Setyanto, R. A., \& Samudro, B. R. (2015). Kajian Pola Pengembangan UMKM di Kampunga Batik Laweyan Melalui Modal Sosial Dalam Menghadapi Perdagangan Bebas Kawasan ASEAN. Jurnal Ilmu Ekonomi Dan Pembangunan, 71- 90.

Siagian, S. P. (2007). Manajemen Sumber Daya Manusia, Edisi Pertama Cetakan Keempatbelas. Jakarta: PT Bumi Aksara.

Simamora, H. (2004). Manajemen sumber daya manusai. Edisi 3. Yogyakarta: Aditya Medika. Sinungan, M. (2005). Produktivitas Apa dan Bagaimana.edisi kedua. Jakarta: PT. Bumi Aksara. Siswanto, S. (2003). Manajemen Tenaga Kerja Indonesia , Pendekatan Administrasi Dan Operasional. Jakarta: PT Bumi Aksara.

Siswati, E. (2017). . The Effect Of Labour Union Towards A Labour Productivity In East Java. Jurnal Ilmu Manajemen dan Akutansi, 56-72.

Sugiyono. (2010). Metode Penelitian Administratif. Bandung : Alfabeta.

Sugiyono. (2012). Statistik Untuk Penelitian. Bandung: Alfabeta.

Sugiyono. (2013). Metode Penelitian Kuantitatif, Kaulitatif dan R\&D. Bandung: Alfabeta.

Sugiyono. (2014). Metode Penelitian Kuantitatif Kualitatif Dan R\&D. Bandung: Alfabeta.

Sutrisno. (2016). Manajemen Sumber Daya Manusia. Jakarta: Pranadamedia Group.

Taufiqoh, B. R., \& Khotimah, I. N. (2018). Batik Sebagai Warisan Budaya Indobnesia . prosiding Senasbasa, 58-65.

Udo, H. B. (2009). Teori Motivasi dan Pengukurannya. Jakarta: PT Bumi Aksara.

Umar, H. (2010). Metode Penelitian bisnis. Bandung: Alphabeta.

Vitrianingsih, \& Khadijah, S. (2017). Analisis pengalamn kerja terhadap kesiapan menghadapi dunia kerja pada mahasiswa program studi D-IV bidan pendidik. Jurnal Edudikara, 251256.

Winardi. (2009). Teori Organisasi dan Pengorganisasian. Jakarta: Rajawali Pers.

Witjaksana, B., \& Hepiyanto, R. (2013). Analisis Komparasi Produktivitas Tenaga Harian dan Borongan . Ektrapolasi Jurnal Teknik sipil, 13-26. 